Portland State University

PDXScholar

\title{
Mitochondrial Physiology of Diapausing and Developing Embryos of the Annual Killifish Austrofundulus Limnaeus: Implications for Extreme Anoxia Tolerance
}

Jeffrey M. Duerr

George Fox University, jduerr@georgefox.edu

Jason E. Podrabsky

Portland State University, podrabsj@pdx.edu

Follow this and additional works at: https://pdxscholar.library.pdx.edu/bio_fac

Part of the Biology Commons, Cell and Developmental Biology Commons, and the Physiology Commons

Let us know how access to this document benefits you.

\section{Citation Details}

Duerr, J.M. \& Podrabsky, J.E. Mitochondrial Physiology of Diapausing and Developing Embryos of the Annual Killifsh Austrofundulus Limnaeus: Implications for Extreme Anoxia Tolerance. J Comp Physiol B (2010) 180: 991.

This Article is brought to you for free and open access. It has been accepted for inclusion in Biology Faculty Publications and Presentations by an authorized administrator of PDXScholar. Please contact us if we can make this document more accessible: pdxscholar@pdx.edu. 


\title{
Mitochondrial physiology of diapausing and developing embryos of the annual killifish Austrofundulus limnaeus: implications for extreme anoxia tolerance
}

\author{
Jeffrey M. Duerr · Jason E. Podrabsky
}

\begin{abstract}
Diapausing embryos of the annual killifish Austrofundulus limnaeus have the highest reported anoxia tolerance of any vertebrate and previous studies indicate modified mitochondrial physiology likely supports anoxic metabolism. Functional mitochondria isolated from diapausing and developing embryos of the annual killifish exhibited $V \mathrm{O}_{2}$, respiratory control ratios (RCR), and P:O ratios consistent with those obtained from other ectothermic vertebrate species. Reduced oxygen consumption associated with dormancy in whole animal respiration rates are correlated with maximal respiration rates of mitochondria isolated from diapausing versus developing embryos. P:O ratios for developing embryos were similar to those obtained from adult liver, but were diminished in mitochondria from diapausing embryos suggesting decreased oxidative efficiency. Proton leak in adult liver corresponded with that of developing embryos but was elevated in mitochondria isolated from diapausing embryos. In metabolically suppressed diapause II embryos, over $95 \%$ of the mitochondrial oxygen consumption is accounted for by proton leak across the inner mitochondrial membrane. Decreased activity of mitochondrial respiratory chain complexes correlates with diminished oxidative capacity of isolated mitochondria, especially during diapause. Respiratory complexes exhibited suppressed activity in mitochondria
\end{abstract}

\footnotetext{
J. M. Duerr $(\bowtie)$

Department of Biology, George Fox University,

Newberg, OR 97132, USA

e-mail: jduerr@georgefox.edu

J. E. Podrabsky

Department of Biology, Portland State University,

P.O. Box 751, Portland, OR 97207, USA
}

with the ATP synthase exhibiting the greatest inhibition during diapause II. Mitochondria isolated from diapause II embryos are not poised to produce ATP, but rather to shuttle carbon and electrons through the Kreb's cycle while minimizing the generation of a proton motive force. This particular mitochondrial physiology is likely a mechanism to avoid production of reactive oxygen species during large-scale changes in flux through oxidative phosphorylation pathways associated with metabolic transitions into and out of dormancy and anoxia.

Keywords ATP synthase - Metabolic depression . Diapause $\cdot$ Anoxia

\section{Introduction}

The embryo of the annual killifish Austrofundulus limnaeus represents the most anoxia-tolerant vertebrate and can survive for months in the complete absence of oxygen at $25^{\circ} \mathrm{C}$ (Podrabsky et al. 2007). This level of anoxia tolerance is two orders of magnitude higher than other anoxia-tolerant vertebrates and suggests new mechanisms for supporting anoxia tolerance in this species. Survival of anoxia is a natural part of the life of A. limnaeus embryos and is associated with entry of the embryos into diapause, a pre-emptive form of metabolic dormancy that is a natural part of their developmental program. Diapause represents a form of intrinsic metabolic depression since its onset is not triggered by environment cues. Entry into diapause is associated with a severe metabolic depression as estimated by both oxygen consumption and heat dissipation (Podrabsky and Hand 1999). In addition, calorimetric:respirometric ratios are elevated during diapause suggesting a significant contribution of anaerobic metabolism to overall heat 
dissipation even under aerobic conditions. Thus, it appears that the metabolic changes associated with dormancy during diapause may also serve to prepare embryos for subsequent exposures to anoxia. The mechanisms that suppress oxidative metabolism during diapause are currently unknown and led us to investigate the physiology of mitochondria isolated from developing and diapausing embryos of A. limnaeus.

There are a maximum of three distinct diapause phases that may occur in annual killifish, only two of which occur in embryos of A. limnaeus, termed diapause II and III (Wourms 1972a, b). Diapause II is developmentally predictable in A. limnaeus and occurs in embryos possessing 38-40 pairs of somites, a beating heart and the foundations of a central nervous system; $80 \%$ or more of the embryos will enter diapause II after 24-26 days of development at $25^{\circ} \mathrm{C}$. Diapause III is obligate for most embryos and occurs just prior to hatching when the embryo is fully developed. This stage of diapause is generally compared with aestivation in frogs. Diapause II embryos are tolerant of long-term anoxia, while diapause III embryos are not (Podrabsky et al. 2007). Importantly, the extreme anoxia tolerance observed in diapause II embryos is retained for at least 4 days of post-diapause II development, but is lost after 8 days of post-diapause II development (Podrabsky et al. 2007). Thus, in this species extreme anoxia tolerance is gained as embryos develop toward and enter diapause II, and then lost by the time embryological development is complete.

Two main strategies for metabolic suppression in anoxia-tolerant animals have been proposed: (1) a reduction in ATP turnover and (2) improved ATP yield of anaerobic metabolism (Hochachka and Somero 2002; Storey and Hochachka 1974). ATP-consuming reactions in the cell can be divided into two groups. The first comprises $70 \%$ of total respiration and includes powering the $\mathrm{Na}^{+} / \mathrm{K}^{+}$-ATPase on the plasma membrane, protein synthesis, mRNA synthesis and $\mathrm{Ca}^{2+}$ cycling. A large proportion of the remaining $30 \%$ is spent on proton leak at the inner mitochondrial membrane (imm) (Rolfe and Brand 1996). Proton leak occurs as a result of limited permeability of the imm to protons and the proton motive force (pmf) that exists across that membrane in energized mitochondria. Pathways that require oxygen (respiration) can also be divided into two groups: mitochondrial (ATP-producing) and non-mitochondrial (which includes oxygen-dependent, non-phosphorylating catabolism in the peroxisome and endoplasmic reticulum) (Bishop et al. 2002). If metabolic depression is to occur while maintaining homeostasis of the cell, then the energy intermediate ATP must be maintained at a steady-state. Therefore, it is postulated that the cell must coordinately down-regulate both energy-producing and energy-consuming reactions. This appears to be the case in diapause II embryos of A. limnaeus, which maintain high $[\mathrm{ATP}] /[\mathrm{ADP}]$ ratios and adenylate energy charge in the face of over a $90 \%$ reduction in oxygen consumption (Podrabsky and Hand 1999). The extent to which control of mitochondrial metabolism may be implicated in supporting metabolic depression during diapause has yet to be explored in A. limnaeus.

During the past decade, both overwintering frogs (Rana) and estivating snails (Helix) have been employed to investigate mitochondrial respiration during metabolic depression. In frogs, isolated skeletal muscle mitochondria exhibited decreases in rates of oxygen consumption and proton leak during overwintering (Boutilier and St-Pierre 2002). In the snail, respiration rates of whole hepatopancreas cells were measured (Bishop and Brand 2000). In control cells, nonmitochondrial oxygen consumption accounted for $45 \%$ and mitochondrial $55 \%$ of total oxygen consumption; in cells from estivating snails (overall metabolism 33\% of normal), non-mitochondrial and mitochondrial respiration each accounted for $50 \%$ of the total respiration rate. In both cases, the strong depression of metabolism reported was the result of a concomitant decrease in rates of both oxygen consumption and proton leak. Suppression of mitochondrial respiration may be achieved in three ways: (1) a decrease in the area of the imm, (2) a decrease in substrate oxidation and a subsequent decline in the pmf, and (3) a decrease in the proton conductance of the imm. Data collected in anuran amphibians suggest that option 2 is the case: a decrease in the reactions that catalyze substrate oxidation was measured in Bufo (Trzcionka et al. 2008) and Rana (St-Pierre et al. 2000a, b). However, it is worth noting that several investigations have found very little difference between proton leak rates in mitochondria isolated from dormant versus active animals. For example, mitochondria isolated from Artemia embryos during diapause exhibit similar respiratory and proton leak rates despite a $97 \%$ reduction in metabolism (Reynolds and Hand 2004).

Our investigation focuses on the bioenergetic status of mitochondria isolated from diapausing embryos of the annual killifish A. limnaeus. We isolated intact mitochondria from six developmental stages corresponding to periods of significant change in whole animal metabolism and morphology: 10 days post-fertilization (dpf), diapause II, post-diapause II, diapause III, larvae, and adults (liver). We measured oxygen consumption rates, phosphate:oxygen ratios, proton leak rates, and respiratory complex enzyme activities in mitochondria isolated from each life stage. We report that mitochondrial respiration is coordinately downregulated and proton leak is elevated during periods of diapause. The respiratory complex activity profile varied as a function of developmental stage, suggesting specific and reversible inhibition of discrete portions of the electron transport chain associated with diapause and with anoxia 
tolerance. These data indicate that diapause is associated with a very unique mitochondrial physiology that is likely poised to protect the cell from production of reactive oxygen species (ROS) and ATP depletion during transitions in metabolism associated with dormancy and exposure to anoxia.

\section{Materials and methods}

Collection, incubation and observation of embryos

Eggs of A. limnaeus were obtained from a laboratory stock of fish through natural spawning activity of adult fish as described by Podrabsky (1999). Briefly, fish were allowed access to spawning trays containing a layer of glass beads 1-2 cm deep (500 $\mu \mathrm{m}$ diameter; Thomas Scientific, Swedesboro, USA) for 2-4 h. Trays were then transferred to a secondary container, the false bottom was removed, and the glass beads were sifted through the fiberglass screen bottom. Eggs retained on the screen were collected using a wide-mouthed plastic pipette. Each spawning event represents embryos collected from 42 pairs of spawning fish.

Embryos were incubated in medium formulated to mimic the ionic composition of natural ponds inhabited by A. limnaeus (Podrabsky et al. 1998; Podrabsky 1999) under normoxic conditions ( $>70 \%$ air saturation). During the first 4 days of development, methylene blue $(0.0001 \%)$ was added to the medium to help reduce bacterial growth. At $4 \mathrm{dpf}$, embryos were treated with $0.01 \%$ sodium hypochlorite to help prevent fungal and bacterial infections and then transferred to embryo medium containing $10 \mathrm{mg} \mathrm{l}^{-1}$ gentamycin sulfate (Podrabsky 1999).

Embryos from at least four separate spawning events were used for each developmental stage. Developmental stages were chosen to represent important physiological stages in the development of A. limnaeus associated with entry into diapause and tolerance of anoxia. Embryos at $10 \mathrm{dpf}$ were used to represent pre-diapause II embryos at the formation of the embryonic axis. Diapause II embryos represent the peak of anoxia tolerance. Post-diapause II development was represented by embryos between 9 and 12 days post-diapause II (dpd). These embryos are actively developing at the maximal rate for this species and have a low tolerance of anoxia. Diapause III embryos represent another stage of metabolic dormancy, but with a low tolerance of anoxia. Finally, larvae were chosen to represent a post-embryonic stage that is acutely sensitive to anoxia. Synchrony of embryos within and between batches was monitored using an inverted compound microscope equipped with Nomarski optics (Leica DMIRB). Mitochondria from adult killifish were obtained from freshly excised whole liver. These mitochondria serve as a control for the isolation procedures and allow for comparisons of adult mitochondria from A. limnaeus to those from other species and to mitochondria isolated from earlier life history stages.

Isolation of mitochondria

We adapted a method for isolating intact skeletal and liver mitochondria from amphibian (Duerr and Hillman 1993) and dogfish shark tissues (Lea and Hillman 1990) for use in embryos and tissues isolated from A. limnaeus. Freshly collected embryos ( $\sim 200$ per batch), larvae ( $\sim 200$ per batch), or excised adult liver were washed using ice-cold isolation buffer $\left[120 \mathrm{mmol} \mathrm{l}^{-1} \mathrm{KCl}, 5 \mathrm{mmol}^{-1}\right.$ TES ( $N$-[tris(hydroxymethyl)methyl]-2-aminoethanesulfonic acid), $1 \mathrm{mmol} \mathrm{l}^{-1}$ EGTA (ethylene glycol-bis(2-aminoethylether)- $N, N, N^{\prime}, N^{\prime}$-tetraacetic acid) and 2\% BSA (bovine serum albumin, fatty acid free), $\mathrm{pH} 7.4$, osmotic pressure $\sim 270 \mathrm{mOsmol} \mathrm{kg} \mathrm{kg}^{-1}$ water]. In order to determine appropriate osmotic strength for isolating intact mitochondria, we measured plasma osmotic pressure in adult killifish $(n=5)$ as $266 \pm 6 \mathrm{mOsmol} \mathrm{kg}^{-1}$ (mean $\pm \mathrm{SD}$ ) using a Wescor vapor pressure osmometer. Livers were manually minced with scissors for $30 \mathrm{~s}$ and transferred to a Potter-type tissue homogenizer. Embryos and larvae were placed directly into the tissue homogenizer following the wash step. Liver samples were subjected to ten passes of the pestle at approximately $200 \mathrm{rpm}$ whereas the more delicate larvae and embryos were subjected to three passes at $200 \mathrm{rpm}$. Tissue homogenates were transferred to clean tubes and centrifuged at $4^{\circ} \mathrm{C}$ for $10 \mathrm{~min}$ at $700 \times g$ to pellet large cellular debris. The resulting supernatant was recovered and filtered through cheesecloth to collect excess lipid, and subjected to centrifugation for $10 \mathrm{~min}$ at $10,000 \times g$ to pellet mitochondria. The superficial light fluffy layer of the pellet was gently washed off and discarded. The darker portion of the pellet was separately resuspended in isolation buffer and subjected to centrifugation for $10 \mathrm{~min}$ at $10,000 \times g$. The resulting pellet was resuspended in ice-cold isolation buffer and spun at $10,000 \times g$ a final time for $10 \mathrm{~min}$. The final pellet was gently resuspended in respiration buffer (120 mmol l-1 $\mathrm{KCl}, 3 \mathrm{mmol} \mathrm{l}^{-1} \mathrm{TES}, 5 \mathrm{mmol} \mathrm{l}^{-1} \mathrm{~K}_{2} \mathrm{HPO}_{4}$, $5 \mathrm{mmol} \mathrm{l}^{-1} \mathrm{MgCl}_{2}, \mathrm{pH} \mathrm{7.4)}$ and stored on ice for at least $30 \mathrm{~min}$ prior to respiration assays. Final concentrations of mitochondria ranged from 10 to $25 \mathrm{mg} \mathrm{ml}^{-1}$. Protein content was quantified using the Pierce MicroBCA protein assay kit (Pierce Biotechnology, Rockford, USA).

\section{Measurement of mitochondrial respiration}

Isolated mitochondria $\left(0.5 \mathrm{mg} \mathrm{ml}^{-1}\right)$ were added directly to $600 \mu \mathrm{l}$ of respiration buffer in a temperature-controlled, water-jacketed respiration chamber (Instech $600 \mathrm{FH}$, Plymouth Meeting, USA) fitted with an $\mathrm{O}_{2}$ microelectrode. 
Data were collected using the polarographic method (Chance and Williams 1955) and recorded digitally using Chart 5.0 (Powerlab). All respiration rates were calculated using data analysis algorithms in Chart 5.0. Assay temperature was maintained at $25^{\circ} \mathrm{C}$. Following a temperatureacclimation period of $3 \mathrm{~min}, 10 \mathrm{mmol} \mathrm{l}^{-1}$ substrate (final concentration) was added, and $\mathrm{O}_{2}$ consumption monitored as state 2 respiration. State 3 respiration $\left(\mathrm{VO}_{2} \max \right)$ was initiated by the addition of $4 \mathrm{mmol}^{-1}$ ADP (final concentration). Oxygen consumption was measured until all ADP was exhausted and state 4 respiration was achieved. Adenylate RCR were calculated by dividing ADP-activated $\mathrm{O}_{2}$ consumption (OXPHOS or state 3) by leak flux (state 4; all ADP converted to ATP) (Kuznetsov et al. 2004; Chance and Williams 1955). P:O ratios were calculated as the number of moles of oxygen atoms $(\mathrm{O})$ required to convert total ADP to ATP. Proton fluxes for NADH-dependent and $\mathrm{FADH}_{2}$-dependent substrates were calculated by multiplying oligomycin-sensitive state 4 oxygen consumption by 10 and 6 , respectively.

Pyruvate + malate, succinate, and glutamate were all tested as metabolic substrates for mitochondria isolated from A. limnaeus. Maximal state 3 respiration rates were achieved using glutamate and succinate as substrates rather than pyruvate + malate (Fig. 1). These data are consistent with what is known about substrate availability in A. limnaeus embryos from previous metabolomics studies (Podrabsky et al. 2007). Under normoxic conditions succinate and pyruvate levels are extremely low and usually not detectable even with highly sensitive techniques such as mass spectroscopy. However, glutamate is always the single



Fig. 1 State 3 respiration in mitochondria isolated from A. limnaeus larvae and adult stages using either glutamate/malate, pyruvate/malate, or succinate as the oxidizable substrate(s). Values are mean $\pm \mathrm{SEM}$, $n=3-10$ most abundant amino acid in A. limnaeus embryos with levels ranging from 1 to $12 \mathrm{mmol} \mathrm{l}^{-1}$ during early development through diapause II (Podrabsky et al. 2007).

\section{Enzyme assays}

Activities of respiratory complexes I, II, IV, and V were quantified in mitochondria isolated from each developmental stage using spectrophotometric assays at $25^{\circ} \mathrm{C}$. Prior to assays, mitochondrial membranes were disrupted by incubation in hypotonic $\mathrm{KCl}$ buffer (osmotic shock; $10 \mathrm{mmol} \mathrm{l}^{-1} \mathrm{KCl}, 10 \mathrm{mmol}^{-1}$ Tris, $\mathrm{pH}$ 7.6) followed by a single freeze-thaw cycle. This pretreatment regimen was sufficient for optimal release of respiratory complexes as repeated freeze-thaw cycles did not improve results (data not shown).

Complexes I and II were measured using a novel and highly sensitive technique (Janssen et al. 2007). Complex I activity was determined by spectrophotometrically measuring the reduction of DCIP (2,6-dichloroindophenol) at $600 \mathrm{~nm}$ in an incubation volume of $1 \mathrm{ml}$ containing $\left(25 \mathrm{mmol} \mathrm{l}^{-1}\right.$ potassium phosphate, $3.5 \% \mathrm{BSA}, 60 \mu \mathrm{mol} \mathrm{l}^{-1}$ DCIP, $70 \mu \mathrm{mol}^{-1}$ decylubiquinone, $1 \mu \mathrm{mol} 1^{-1}$ antimycin-A and $0.2 \mathrm{mmol}^{-1} \mathrm{NADH}, \mathrm{pH}$ 7.8). Mitochondria $(0.25 \mathrm{mg}$ $\mathrm{ml}^{-1}$ ) were preincubated in an aliquot of incubation buffer without NADH. After 3 min, NADH was added and absorbance measured at $30 \mathrm{~s}$ intervals for $4 \mathrm{~min}$. Changes in DCIP reduction were calculated from changes in absorbance using an extinction coefficient of $19.1 \mathrm{mmol}^{-1} \mathrm{~cm}^{-1}$. After $4 \mathrm{~min}, 5 \mu \mathrm{mol}^{-1}$ (final concentration) of rotenone was added and absorbance measured again for $4 \mathrm{~min}$. Complex II activity was also determined by monitoring reduction of DCIP at $600 \mathrm{~nm}$ in a volume of $1 \mathrm{ml}$ containing $80 \mathrm{mmol}^{-1}$ potassium phosphate, $1 \%$ BSA, $2 \mathrm{mmol} \mathrm{l}^{-1}$ EDTA, $0.2 \mathrm{mmol}^{-1}$ ATP, $10 \mathrm{mmol} \mathrm{l}^{-1}$ succinate, $0.3 \mathrm{mmol}^{-1} \mathrm{KCN}, 80 \mu \mathrm{mol} \mathrm{l}^{-1}$ DCIP, $50 \mu \mathrm{mol} \mathrm{l}^{-1}$ decylubiquinone, $1 \mu \mathrm{mol}^{-1}$ antimycin-A, and $3 \mu \mathrm{mol} \mathrm{l}^{-1}$ rotenone, $\mathrm{pH}$ 7.8. Aliquots of mitochondria $\left(0.25 \mathrm{mg} \mathrm{ml}^{-1}\right)$ were preincubated in reaction buffer without $\mathrm{KCN}$ and substrate for $10 \mathrm{~min}$, after which $\mathrm{KCN}$ and succinate was added to initiate the reaction. Absorbance was measured at $1 \mathrm{~min}$ intervals for $5 \mathrm{~min}$ and converted to $\mathrm{mmol}$ reduced DCIP using an extinction coefficient of $19.1 \mathrm{mmol} \mathrm{l}^{-1} \mathrm{~cm}^{-1}$.

Complex IV activity was estimated using the method of Hodges and Leonard (1974). Mitochondria $\left(0.25 \mathrm{mg} \mathrm{ml}^{-1}\right)$ were preincubated in $1 \mathrm{ml}$ of $50 \mathrm{mmol} \mathrm{l}^{-1} \mathrm{KHPO}_{4}$ and $0.3 \%$ digitonin $(\mathrm{pH} 7.5)$. Reactions were initiated by addition of $0.45 \mathrm{mmol} \mathrm{l}^{-1}$ reduced cytochrome $c$ and absorbance at $550 \mathrm{~nm}$ measured every $30 \mathrm{~s}$ for $5 \mathrm{~min} .4 \mathrm{mM}$ $\mathrm{KCN}$ was added at the end of the assay to determine the OD of completely oxidized cytochrome $c$. Rates of cytochrome $c$ oxidation were determined from initial rates of change in 
absorbance by using an extinction coefficient of $18.5 \mathrm{mmol} \mathrm{l}^{-1} \mathrm{~cm}^{-1}$.

Complex V (ATP synthase) activity was estimated using an ATP regenerating system described by Rosing et al. (1975). Mitochondria were diluted to a final concentration of $0.25 \mathrm{mg} \mathrm{ml}^{-1}$ in a sucrose-Tris-EDTA buffer $\left(33 \mathrm{mmol}^{-1}\right.$ Tris-acetate, $83 \mathrm{mmol}^{-1}$ sucrose, $10 \mathrm{mmol} \mathrm{l}^{-1} \mathrm{MgCl}_{2}$, $2 \mathrm{mmol} \mathrm{l}^{-1}$ ATP, $1.5 \mathrm{mmol} \mathrm{l}^{-1}$ phosphoenolpyruvate, $0.17 \mathrm{mmol}^{-1} \mathrm{NADH}, 6$ units of pyruvate kinase and 12 units of lactate dehydrogenase at $\mathrm{pH}$ 7.2). ATPase activity was calculated from oligomycin-sensitive NADH oxidation measured spectrophotometrically at $340 \mathrm{~nm}$. Measurements were recorded every $10 \mathrm{~s}$ for $4 \mathrm{~min}$.

Statistical analyses

All respiratory rates were normalized relative to total protein to accommodate differences in preparatory yield. Statistical analyses were conducted using Prism 5.0b for Macintosh (GraphPad Software 2009). Each experiment was repeated two to three times using mitochondria from different pools of 200 animals. Three to five replicate measures $(n)$ for each treatment in each experiment were obtained. Significant differences were determined using one-way ANOVA followed by Tukey's HSD post hoc tests for multiple comparisons. Correlation analysis was used to determine degree of covariation in instances where both variables were measured. Unless otherwise noted, a value of $P<0.05$ was considered statistically significant.

\section{Results}

Respiration rates of isolated mitochondria

The isolation techniques employed produced a fraction of high quality "coupled" intact mitochondria with the ability to oxidize multiple substrates. Substrate preference for NADH-linked substrates was established by measuring state 3 respiration in the presence of a final concentration of either $10 \mathrm{mmol} \mathrm{l}^{-1}$ glutamate and $2 \mathrm{mmol} \mathrm{l}^{-1}$ "sparker" malate or $10 \mathrm{mmol}^{-1}$ pyruvate and $2 \mathrm{mmol}^{-1}$ malate. We also assessed $\mathrm{FADH}_{2}$-linked respiration using succinate $\left(10 \mathrm{mmol}^{-1}\right)$. State 3 respiration rates were greatest when glutamate/malate or succinate were used as substrates (Fig. 1). Mitochondrial state 3 respiration ranged from a minimum of $\sim 5 \mathrm{nmol} \mathrm{O}_{2} \mathrm{mg}_{\text {protein }}{ }^{-1} \mathrm{~min}^{-1}$ (10 dpf) to a maximum of $60 \mathrm{nmol} \mathrm{O}_{2} \mathrm{mg}_{\text {protein }}{ }^{-1} \mathrm{~min}^{-1}$ (adult liver), a range of nearly tenfold in the presence of either glutamate/malate or succinate as the oxidizable substrate (Fig. 2). All the early life stages examined in this study exhibited rates of state 3 respiration that were submaximal compared to those obtained from mitochondria isolated


Life Stage

Fig. 2 State 3 respiration in mitochondria isolated from A. limnaeus at various developmental stages using either (a) glutamate/malate or (b) succinate as the oxidizable substrate(s). Values are mean $\pm \mathrm{SEM}$, $n=5$. Bars with different letters are statistically different (one-way ANOVA, Tukey's post hoc, $P<0.05$ )

from adult liver. Maximal rates of state 3 respiration are greatly reduced independent of substrate oxidized during diapause II and diapause III relative to post-diapause II embryos, larvae (approximately equal though sub-maximal), and adult liver (maximal).

\section{Respiratory control ratios}

Mitochondrial respiration (leak) in the presence of substrates (state 2) is augmented by the addition of ADP (state 3/OXPHOS) by a factor defined as the adenylate RCR (Kuznetsov et al. 2004). RCRs ranged from approximately 2.3 for pre-adult whole embryo or larvae to approximately 4.4 for adult liver (Fig. 3). Maximal RCR values were obtained from adult livers using either glutamate/malate or succinate as the oxidizable substrate. No significant differences were measured for RCRs among mitochondria 

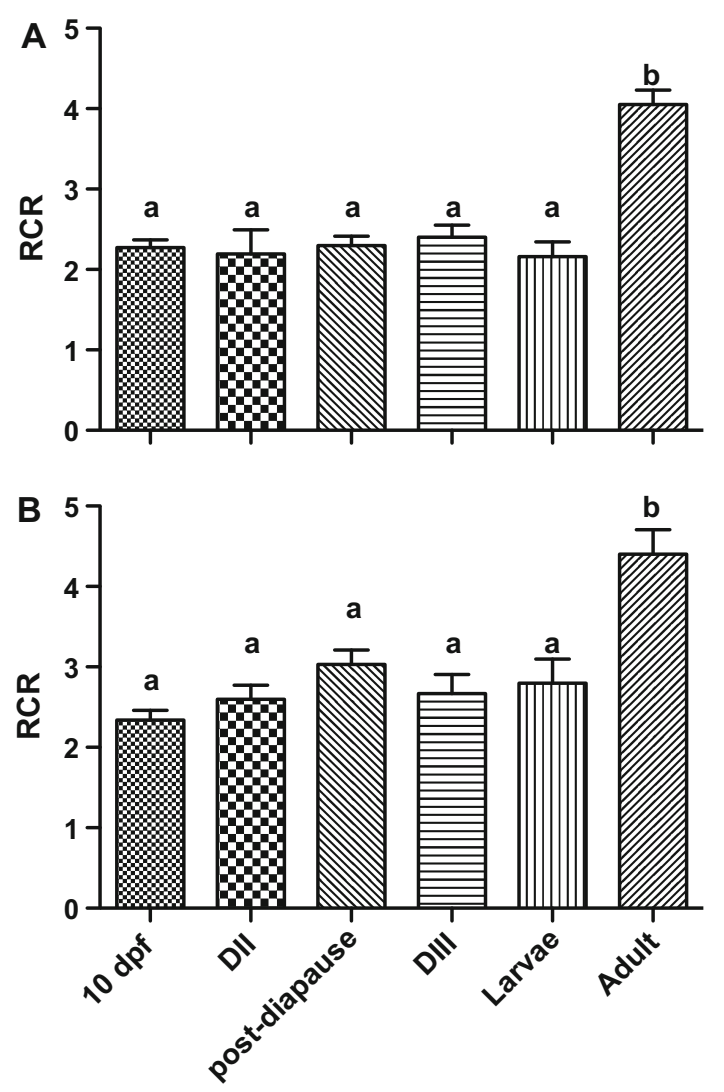

Life Stage

Fig. 3 Respiratory control ratios, calculated as state 3/state 4 respiration in mitochondria isolated from A. limnaeus at various developmental stages using either (a) glutamate/malate or (b) succinate as the oxidizable substrate(s). Values are mean \pm SEM, $n=5$ (one-way ANOVA, Tukey's post hoc, $P<0.05$ )

isolated from pre-adult stages. It should be noted that similar RCRs were obtained from mitochondria isolated from adult liver using a sucrose-based medium (data not shown), whereas mitochondria isolated from larvae and embryos displayed lower RCRs. We therefore used a $\mathrm{KCl}$ medium for all mitochondrial preparations.

Oxidative efficiency of isolated mitochondria

\section{Phosphate:oxygen ratios}

Mitochondrial oxidative efficiency was assessed by calculating $\mathrm{P}: \mathrm{O}$ ratios. $\mathrm{P}: \mathrm{O}$ ratios were calculated by dividing the number of moles of ADP phosphorylated by the number of moles of oxygen atoms consumed. Ratios are presented as obtained using NADH-linked substrate (glutamate/malate) or $\mathrm{FADH}_{2}$-linked substrate (succinate) from mitochondria isolated from various life stages. Figure 4 summarizes the results. Ratios ranged from 0.95 for diapause II embryo mitochondria to 2.2 for mitochondria from post-diapause II

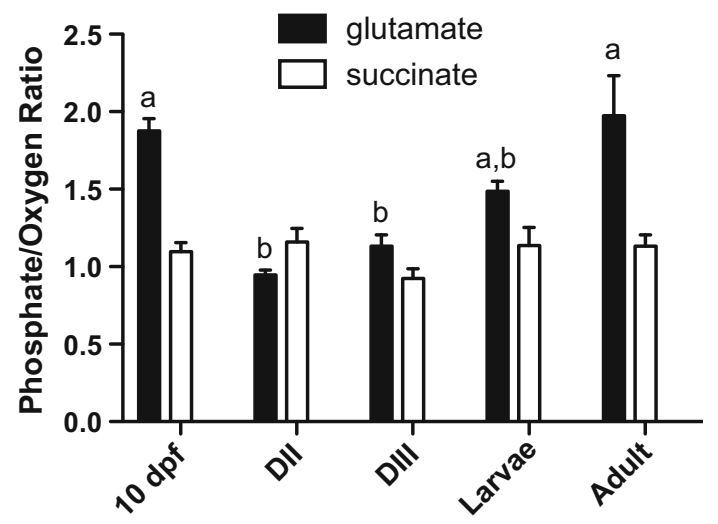

Life Stage

Fig. 4 P:O ratios in mitochondria isolated from A. limnaeus at various developmental stages using either (a) glutamate/malate or (b) succinate as the oxidizable substrate(s). Values are mean $\pm \mathrm{SEM}, n=5$. Bars with different letters are statistically different (one-way ANOVA, Tukey's post hoc, $P<0.05$ )

embryos and adult liver when using glutamate/malate as substrates. When using succinate as a substrate, $\mathrm{P}: \mathrm{O}$ ratios ranged from 0.97 for diapause III embryo mitochondria to 1.31 for adult liver mitochondria. All values fell within the theoretical maximum range of 2.5 for NADH-linked substrates and 1.5 for $\mathrm{FADH}_{2}$-linked substrates. There were no significant differences among P:O ratios when utilizing succinate as a substrate, but when utilizing glutamate/malate as substrate, P:O ratios were significantly lower $(P<0.05)$ in mitochondria from DII and DIII embryos.

\section{Proton leak}

Proton leak was assessed for mitochondria isolated from each life stage of A. limnaeus (Fig. 5). Proton leak for $\mathrm{NADH}$-dependent substrates and $\mathrm{FADH}_{2}$-dependent substrates was calculated by multiplying the state 4 mitochondrial oxygen consumption rate (in moles of oxygen atoms) in the presence of oligomycin by 10 and 6 , respectively (St-Pierre et al. 2000a, b), assuming no slip in proton pumps and a steady-state membrane potential (Brand et al. 1994). Proton leak rates were significantly elevated in both diapause II and diapause III relative to both $10 \mathrm{dpf}$ and adult when measured in the presence of glutamate/malate; whereas there were no significant differences among proton leak rates in the various life stages when using succinate as a substrate.

\section{Activity of electron transport chain complexes}

Respiratory complex activity was assessed for complex I (NADH-ubiquinone oxidoreductase), complex II (succinate:ubiquinone oxidoreductase), complex IV [cytochrome $c$ oxidase (CCO)] and complex V (ATP synthase) (Fig. 6). 

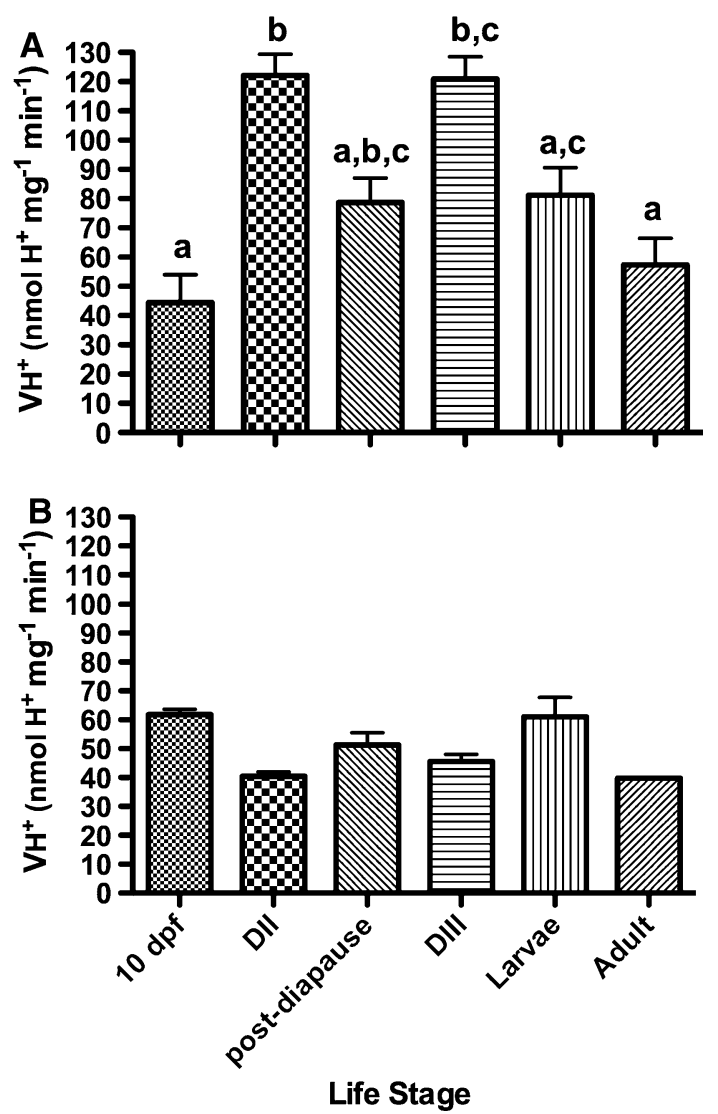

Fig. 5 Proton leak in mitochondria isolated from A. limnaeus at various developmental stages using either (a) glutamate/malate or (b) succinate as the oxidizable substrate(s). Values are mean \pm SEM, $n=5$ (one-way ANOVA, Tukey's post hoc, $P<0.05$ )

Complex I activity was significantly lower $(P<0.05)$ in mitochondria isolated from $10 \mathrm{dpf}$, diapause II, diapause III, and post-diapause II embryos relative to mitochondria isolated from whole larvae and adult liver. Complex II activity was significantly lower $(P<0.05)$ in mitochondria isolated from diapausing embryos relative to $10 \mathrm{dpf}$ and post-diapause II embryos, larvae, and adult liver. Complex IV activity was significantly lower $(P<0.05)$ in mitochondria isolated from diapausing embryos compared to mitochondria from larvae and adult liver. Complex V activity was significantly diminished $(P<0.05)$ in mitochondria isolated from diapause II and diapause III embryos relative to mitochondria isolated from non-diapausing embryos.

\section{Discussion}

Overall quality and properties of mitochondria isolated from A. limnaeus

The methods used to isolate mitochondria in this study produced high quality "coupled" mitochondria with the ability to oxidize multiple substrates. Rates of state 3 respiration (Fig. 2) and RCR values (Fig. 3) obtained for mitochondria isolated from adult liver of A. limnaeus were consistent with those recently reported for isolated mitochondria from adult liver of the killifish Fundulus heteroclitus (Fangue et al. 2009). Moreover, RCR values are consistent with those published on mitochondria from liver and gill tissue of other ectothermic animals: 2.0 for lamprey liver, 1.5 for frog liver (Savina et al. 2006), 2.1 for catfish liver (Mishra and Shukla 1994), and 3.0 for gill tissue from an Antarctic sessile bivalve (Heise et al. 2003). RCR values ranged from 2.3 to 4.4 for mitochondria obtained from larvae and embryos. While these values are lower than those obtained from adult liver, lower RCRs are expected in the context of the rest of the data presented (e.g. lower respiratory complex activity), and they fall well within the range of RCR values reported for a variety of other ectotherms as listed above. In addition, mitochondria isolated from all annual killifish preparations displayed at least a fourfold increase in respiration rate upon addition of the uncoupler FCCP (data not shown), which suggests good quality mitochondria capable of maintaining an electrochemical potential across their inner membrane.

Rates of mitochondrial oxygen consumption varied as a function of life stage in A. limnaeus (Fig. 2) and approximated the pattern of oxygen consumption observed in whole animals as previously reported (Podrabsky and Hand 1999). For example, whole animal oxygen consumption of 10 and $9-12$ dpd (post-diapause) embryos is about 2.4 and $24 \mathrm{nmol} \mathrm{O}_{2} \mathrm{~min}^{-1} 200$ embryos $^{-1}$, respectively-a tenfold difference (Podrabsky and Hand 1999). Oxygen consumption of isolated mitochondria from 9 to $12 \mathrm{dpd}$ (postdiapause) embryos was sixfold greater than that of mitochondria isolated from $10 \mathrm{dpf}$ embryos. Furthermore, mitochondrial respiratory rates increased proportionately with whole animal respiration rates, suggesting similar mitochondrial yields and performance. While rates of oxygen consumption are higher in isolated mitochondria compared to whole embryos, the higher rates are likely a reflection of increased concentrations of substrate and oxygen present in the respiration medium.

Intrinsic depression of mitochondrial respiration during diapause

A large portion of the depression of oxidative metabolism observed during diapause in whole embryos of A. limnaeus can be accounted for by the intrinsic properties of their isolated mitochondria. Estimates of metabolic depression associated with diapause derived from values of state 3 respiration in isolated mitochondria are consistent with values obtained for whole embryos. The rate of oxygen consumption of early embryos of $A$. limnaeus peaks at $8 \mathrm{dpf}$ and 
Fig. 6 Respiratory complex activity of mitochondria isolated from A. limnaeus at various developmental stages. Values are mean \pm SEM, $n=3-5$. Bars with different letters are statistically different (one-way ANOVA, Tukey's post hoc, $P<0.05)$
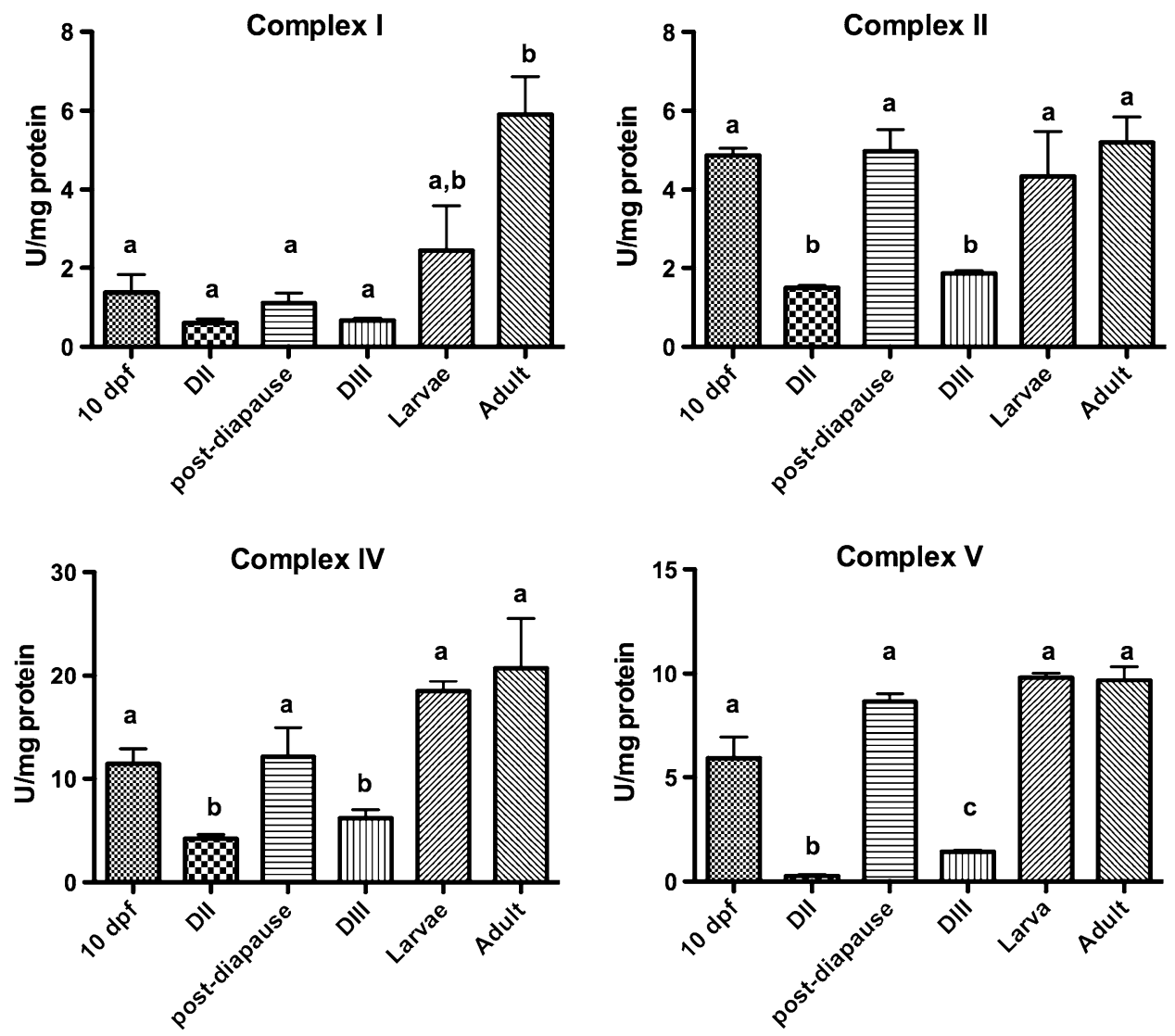

Life Stage

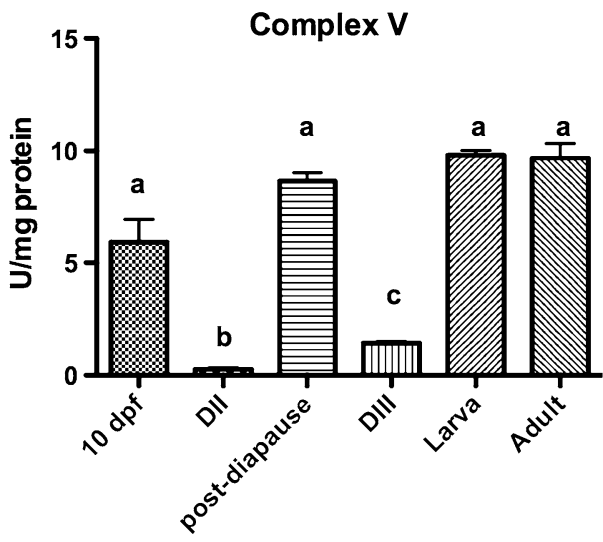

Life Stage then declines as embryos develop toward diapause II (Podrabsky and Hand 1999). Oxygen consumption is depressed by about $67 \%$ when embryos enter diapause II at $24 \mathrm{dpf}$ compared to embryos at $10 \mathrm{dpf}$. Comparison of isolated mitochondrial respiration from these same developmental stages yields similar results of an 18 and $61 \%$ decrease in oxygen consumption in the presence of glutamate/malate and succinate as oxidizable substrates, respectively. Rates of oxygen consumption increase dramatically within 3 days of exit from diapause II in whole embryos, and state 3 respiration values in mitochondria isolated from embryos at 9-12 dpd increased by approximately eightfold with either glutamate/malate or succinate as substrate. For those embryos that entered diapause III, rates of oxygen consumption decreased by $84 \%$ compared with peak rates in whole embryos at $21 \mathrm{dpd}$. Mitochondrial state 3 oxygen consumption rates for diapause III embryos decreased by 75 and 54\% compared to rates for 9-12 dpd embryos when measured in the presence of glutamate/malate and succinate, respectively. Overall, these data on rates of mitochondrial oxygen consumption suggest that mitochondrial oxidative capacity is reversibly down-regulated in sync with the bioenergetic requirements of diapause II and III, and normal development in A. limnaeus.
Phosphorylation efficiency and metabolic dormancy

One stoichiometric measure of mitochondrial oxidative phosphorylation (OxPhos) efficiency is the phosphate:oxygen $(\mathrm{P}: \mathrm{O})$ ratio, which provides an estimate of the moles of ATP produced per mole of oxygen consumed. The current consensus is that the maximum $\mathrm{P}: \mathrm{O}$ ratios for NADHlinked and $\mathrm{FADH}_{2}$-linked substrates are approximately 2.3 and 1.4, respectively (Brand 2005). Mitochondria isolated from adult liver of A. limnaeus and embryos 9-12 dpd appear to be highly efficient with $\mathrm{P}: \mathrm{O}$ ratios of 2.2 for $\mathrm{NADH}$-linked substrate and 1.3 for $\mathrm{FADH}_{2}$-linked substrate (Fig. 4). However, phosphorylation efficiency of isolated mitochondria varies during development and is significantly lower $(P<0.05)$ during diapause II and III when utilizing glutamate/malate as substrate. These low P:O ratios strongly indicate that mitochondrial phosphorylation efficiency is lower (intrinsic uncoupling) in diapausing embryos compared with more metabolically active life history stages. This result is not surprising in light of the extremely low activity of the ATP synthase (complex V) observed in diapausing embryos (Fig. 7).

There are two mechanisms postulated to explain less than optimum P:O ratios (Brand 2005). First, proton pumps 




Fig. 7 Relationship between complex $\mathrm{V}$ activity versus proton leak in mitochondria isolated from various developmental stages of A. limnaeus. Values plotted are mean \pm SEM, $n=3-5$

may 'slip', meaning that fewer protons are pumped across the imm per pair of electrons transferred. Presently, evidence of slip in vivo exists only for CCO (Murphy and Brand 1987). A second way P:O ratios may be reduced is due to increased permeability of the mitochondrial inner membrane to protons (proton leak). In either case, fewer protons are available to drive ATP synthesis. Diminished P:O ratios observed during diapause II and III may reflect regulation of OxPhos by maintaining the mitochondrial inner membrane potential $\left(\Delta \Psi_{\mathrm{m}}\right)$ at low values despite high intramitochondrial ATP/ADP ratios (Kadenbach 2003). An exponential increase in ROS has been measured in mitochondria at $\Delta \Psi_{\mathrm{m}}>140 \mathrm{mV}$ (Korshunov et al. 1997; Addabbo et al. 2009). ROS generation (and the subsequent cellular damage caused by ROS), may be minimized by increasing potential-dependent slip in CCO (Papa et al. 1997). Because diapause is not triggered by external factors, such as hypoxia, increased proton slip may be a strategy to minimize ROS formation during transitions in metabolic rate associated with entry or exit from dormancy or exposure to anoxic conditions.

Mitochondrial proton leak and metabolic dormancy

Mitochondrial oxygen consumption in the absence of ATP synthesis is driving a futile steady-state cycle of proton pumping and proton leak across the inner membrane. There is a large species-dependent variation in proton leak in isolated mitochondria, but it averages approximately $20 \%$ of total respiration (Brand 2005). Proton leak in mitochondria isolated from Baltic lamprey hepatocytes can represent as much as 50\% of total cellular respiration (Savina and Gamper 1998). Rates of proton leak in A. limnaeus adult liver and in actively developing embryos (Fig. 5) are comparable to those reported for liver mitochondria from the killifish F. heteroclitus (Fangue et al. 2009), common carp (Jastroch et al. 2007), and shark (Duong et al. 2006). In addition, the contribution of proton leak to overall rates of oxygen consumption in mitochondria isolated from adult liver are consistent with previously published data and varied from 10 to $15 \%$ with glutamate/malate provided as substrate.

Proton leak rates in mitochondria isolated from diapause II and diapause III embryos of A. limnaeus were significantly elevated relative to estimates obtained for early embryos (10 dpf) and adult liver when glutamate/malate, but not when succinate, was utilized as substrate (Fig. 5). The substrate-dependence of proton leak rates in diapausing embryos suggests that respiratory complex I, upstream of succinate dehydrogenase, may make a significant contribution to proton leak during diapause. While the precise nature of basal proton leak through the imm remains unclear, proton leak rates have been positively correlated with adenine nucleotide transporter (ANT) density (Brand et al. 2005) and levels of phosphorylated CCO (Papa et al. 1997). Some mitochondria express specialized proton-conducting transporters that effectively uncouple mitochondria (UCPs). UCP-containing mitochondria are best described in brown adipose tissue of newborn humans and hibernating mammals (see Cannon and Nedergaard 2004) where uncoupled mitochondria provide supplemental metabolic heat. The mechanism for increased proton leak observed during diapause in A. limnaeus remains undetermined at this time. The present investigation does not include measurements of mitochondrial membrane potential, and thus proton conductances ( $\mathrm{nmol} \mathrm{H} \mathrm{H}^{+} /$min per mg protein per $\mathrm{mV}$ ) cannot be computed. The possibility of proton conductance varying as a function of life-stage-specific changes in mitochondrial membrane potential cannot be discounted and will be the focus of future investigations.

In A. limnaeus, elevated proton leak during diapause may represent an additional mechanism for transiently minimizing the production of ROS during metabolic transitions. Whole-embryo AMP increases at the onset of diapause II (Podrabsky and Hand 1999) and it has been shown in rat skeletal muscle mitochondria that AMP can allosterically act on the ANT to induce a proton leak (Cadenzas et al. 2000). An increase in proton leak, postulated as preventing high $\Delta \Psi_{\mathrm{m}}$ and thereby reducing rates of electron transport chain ROS production, has also been documented in the dwarf Siberian hamster during daily torpor relative to normothermic control animals (Brown et al. 2007). In contrast, studies conducted on isolated overwintering frog skeletal muscle indicate decreased proton leak during hibernation (Boutilier and St-Pierre 2002; Kayes et al. 2009). However, decreased proton leak was not achieved primarily by alterations in proton conductance, but rather secondarily via a reduction in electron transport activity and thereby $\Delta \Psi_{\mathrm{m}}$ (Boutilier and St-Pierre 2002). Similar results were obtained in mitochondria isolated from the hepatopancreas of the aestivating snail Helix aspersa (Bishop and Brand 2000). In arctic ground squirrels 
(Spermophilus paryii), no change in proton leak was observed in mitochondria during hibernation, but instead reduced oxygen consumption was the consequence of reduced substrate oxidation (Barger et al. 2003). Elevated proton leak during metabolic dormancy is counterintuitive, and may appear as a waste of energy at a time when energyproducing pathways are limited. For this reason, we suggest that this trait must have adaptive value for survival, and the most likely reason is to avoid ROS production during transitions in metabolic rate associated with diapause and exposure to anoxia.

Intrinsic mechanisms to reduce oxidative metabolism during diapause

Metabolic control analysis has been effectively employed to investigate the role of mitochondria in all forms of metabolism (Hafner et al. 1990). By employing the principles of "top-down" metabolic control analysis, mitochondrial oxidation can be divided into three components: (1) substrate oxidation (substrate transport, Kreb's cycle, and the electron transport chain), (2) phosphorylation (ATP synthase, ATPases, adenylate transport), and (3) proton leak. Metabolic depression is frequently associated with changes in the activity of the components of the substrate oxidation and phosphorylation apparatus. One of the first studies to examine the basis of intrinsic decreases in mitochondrial respiration in an isolated cell system used hepatopancreas cells from the snail H. aspersa (Bishop et al. 2002). Their results indicated that $75 \%$ of the total response of mitochondrial respiration to aestivation occurs through changes in substrate oxidation, with the remaining $25 \%$ occurring through changes is ATP turnover. More specifically, Stuart et al. (1998) found that CCO activity from the estivating snail (Cepaea nemoralis) decreased by $84 \%$ relative to active controls. Investigations into mechanisms of metabolic depression using lamprey liver mitochondria indicate that reversible alterations in mitochondrial function are significant and include low activity of the respiratory chain, elevated NADH, and leaky mitochondrial membranes (Savina et al. 2006). In this study the authors also speculate that a high $\mathrm{NADH} / \mathrm{NAD}^{+}$ratio inhibits pyruvate oxidation and that complex I and pyruvate dehydrogenase may be inhibited via reversible phosphorylation. Reduced aerobic activity of hibernating common frogs (Rana temporaria) is accompanied by reductions in the activities of citrate synthase, lactate dehydrogenase, complex I and complex II (Boutilier and St-Pierre 2002) as well as the reversible inhibition of the $\mathrm{F}_{1} \mathrm{~F}_{0}$-ATPase (St-Pierre et al. 2000a, b), all of which contribute to a decreased $\Delta \Psi_{\mathrm{m}}$. Suppression of metabolism during diapause in gall fly larvae (which experience both freezing and hypoxia/anoxia) is associated with a decrease in CCO activity, which in turn is correlated with a downregulation of CCO subunit I mRNA levels (McMullen and Storey 2008).

Our investigation into the activity of the electron transport chain in isolated mitochondria from the annual killifish is summarized in Fig. 6. Complex I (NADH-ubiquinone oxidoreductase) levels are significantly lowered in all embryonic mitochondria relative to larval and adult mitochondria, whereas complex II (succinate:ubiquinone oxidoreductase) activity is significantly lower only in diapausing embryos suggesting that $\mathrm{FADH}_{2}$-linked substrates are most important during active stages of development and that NADH-linked substrates are also utilized by larvae and adult liver. Active suppression of complex I may be another component of a general strategy to minimize ROS production as complex I has been implicated as a major source of ROS during active respiration (Brooks 2005). It is also possible that suppression of complex I is necessary simply because it strongly contributes to mitochondrial respiration. Complex I has been demonstrated to be tightly regulated by PKA-dependent phosphorylation (Papa et al. 2008).

Consistent with findings reported for diapausing gall fly larvae and snail hepatopancreas, CCO activity is significantly lower during diapause in annual killifish embryos. This may be a result of reversible biochemical modification or a decrease in CCO mRNA levels and/or translation. Earlier application of metabolic control analysis indicated excess capacity of CCO and little 'control strength' (Groen et al. 1982), though more recent studies conducted in living cells using the same metabolic control analysis indicate a low reserve of $\mathrm{CCO}$ and thus $\mathrm{CCO}$ would represent a significant controlling site of respiration (Villani and Attardi 1997). Suppression of CCO activity in the annual killifish may represent an important component of the regulation of $\Delta \Psi_{\mathrm{m}}$ by the 'second mechanism' of respiratory control, formally proposed by Kadenbach et al. (2009). Unlike classical respiratory control, in which high $\Delta \Psi_{\mathrm{m}}$ inhibits ATP synthesis, the second mechanism posits allosteric inhibition of phosphorylated CCO maintains $\Delta \Psi_{\mathrm{m}}$ at low values $(<140 \mathrm{mV})$ independently of $\Delta \Psi_{\mathrm{m}}$. Reversible phosphorylation of mitochondrial proteins is well established and is a likely mechanism for regulation (Pagliarini and Dixon 2006). Phosphorylation sites for complexes I-V have been identified and correlation of phosphorylation with changes in oxidative physiology has been documented in some instances (Kadenbach et al. 2009). It is not unreasonable to expect any stimulation of cells activating signaling pathways will also direct changes in mitochondrial physiology as a means to adapt OxPhos to altered cellular energy requirements.

Implications for tolerance of anoxia

ATP synthase activity is reduced to nearly undetectable levels in A. limnaeus during diapause II and is significantly 
reduced during diapause III relative to non-diapausing life stages (Fig. 6). Boutilier and St-Pierre (2002) reported a reversible inhibition of ATP synthase activity in hibernating common frogs ( $R$. temporaria) experiencing prolonged hypoxia. During periods of low $\mathrm{O}_{2}$, the activity of the respiratory chain is consequently reduced which may result in the reverse operation of the ATP synthase, and the net consumption of ATP. Reversal of proton pumping by the ATP synthase was first described by Scott and Nicholls (1980) in mitochondria isolated from synaptosomal cytoplasm. Inhibition of both the respiratory chain and ATP synthase, with rotenone and oligomycin, respectively, resulted in a lower $\Delta \Psi_{\mathrm{m}}$ relative to inhibition of the respiratory chain alone, strongly implicating the ATP synthase as a proton-translocating ATP consumer during periods of hypoxia/anoxia. Thus, the profound inhibition of ATP synthase activity during diapause in killifish is likely a mechanism to reduce or prevent ATP consumption by the ATP synthase during diapause and under exposure to anoxia, when rates of OxPhos are extremely limited.

Figure 7 illustrates a coincident reduction in ATP synthase activity and increase in proton conductance in mitochondria isolated from various developmental stages of A. limnaeus: as embryos enter diapause and respiratory chain activity is attenuated and ATP synthase activity is suppressed. We suggest this will prevent any possible corrective ATP-consuming restoration of $\Delta \Psi_{\mathrm{m}}$ by the ATP synthase. At the same time, proton leak is elevated to lower $\Delta \Psi_{\mathrm{m}}$, which likely acts to reduce ROS formation during periods of unpredictable oxygen tensions or as embryos exit from diapause. While the precise mechanism of proton leak cannot be directly inferred from our data, our data may implicate complex IV (CCO) relative to proton slip, as complex IV retains the highest activity at any given developmental stage in A. limnaeus and a decrease in $\mathrm{H}^{+} / \mathrm{e}^{-}$stoichiometry at high pmf has been experimentally verified for complex IV in other organisms by several groups (see Kadenbach et al. 2009).

Taken together the data presented in this paper suggest a unique metabolic role for mitochondria during metabolic dormancy associated with diapause in embryos of A. limnaeus. Levels of electron transport chain complexes are low, ATP synthase activity is drastically reduced, and proton leak rates are increased in mitochondria isolated from diapause II embryos. This is clearly not consistent with a role for mitochondria in OxPhos, but suggests an alternate role. Although high levels of OxPhos are not required during diapause, the metabolic transformations associated with the TCA cycle are likely still required, and metabolomics evidence (Podrabsky et al. 2007) suggests at least limited TCA cycle activity during exposure of embryos to anoxia. Thus, we hypothesize that mitochondria in anoxic diapause II embryos are poised to allow limited TCA cycle activity by maintaining a low membrane potential across the imm (mitochondrial import mechanisms dependent upon $\Delta \Psi_{\mathrm{m}}$ must be preserved in the absence of oxygen) by virtue of the ATP synthase functioning at a low rate and proton leak serving to diminish membrane potential and allow continued flux through the system. In addition, leaky imms and low electron transport chain activity likely limit production of ROS during diapause and especially during major transitions in metabolism associated with exit from diapause and exposure to fluctuations in oxygen tension. Increased proton leak may result from changes in the fatty acid composition of the inner membrane, increased uncoupling protein (UCP) expression, and/or changes in the surface area of the cristae.

It is worth noting that regulation of mitochondrial OxPhos is only one part of a presumed suite of characters that support long-term tolerance of anoxia. This is illustrated by the fact that diapause II and diapause III embryos share many similarities in their mitochondrial physiology, yet diapause II embryos are highly tolerant of anoxia while diapause III embryos can survive for only a couple of days. Thus, the regulation of mitochondrial metabolism is likely critical for the initial survival of embryos exposed to anoxia, but other mechanisms are likely responsible for long-term survival.

\section{Summary}

In summary, we have isolated intact functional mitochondria from the adult and embryonic forms of the annual killifish, A. limnaeus. Mitochondrial $\mathrm{VO}_{2}, \mathrm{RCRs}$, and P:O ratios are comparable to those obtained from other ectothermic vertebrate species. Respiration of isolated mitochondria from diapausing embryos is significantly lower relative to mitochondria isolated from more metabolically active stages including $10 \mathrm{dpf}$, post-diapause, and larval. Proton leak rates are greater in mitochondria isolated from diapausing embryos relative to mitochondria isolated from other life stages, which may reflect changes in membrane conductance designed to minimize oxidative damage. Decreased activity of mitochondrial respiratory chain complexes is also correlated with diminished oxidative capacity of mitochondria isolated from developing annual killifish, especially during diapause. Complexes I, II, IV and V all exhibited reversible suppression of activity. Complex V (ATP synthase) exhibited the greatest inhibition during diapause. Specifically, complexes IV and V may represent the predominate sites of regulation of mitochondrial respiration. The precise biochemical nature of the regulation of mitochondrial respiration remains to be elucidated, but likely involves reversible phosphorylation of regulatory subunits of respiratory complexes directed by presently undefined cell signaling pathways. 
Acknowledgments This work was supported by National Science Foundation grant IOB-0344578 to JEP and a Faculty Research Development Grant from George Fox University to JMD. The authors also wish to thank S.S. Hillman for helpful discussions and technical advice.

\section{References}

Addabbo F, Montagnani M, Goligorsky MS (2009) Mitochondria and reactive oxygen species. Hypertension 53:885-892

Barger JL, Brand MD, Barnes BM, Boyer BB (2003) Tissue-specific depression of mitochondrial proton leak and substrate oxidation in hibernating arctic ground squirrels. Am J Physiol Integr Comp Physiol 284:R1306-R1313

Bishop T, Brand MD (2000) Processes contributing to metabolic depression in hepatopancreas cells from the snail Helix aspersa. J Exp Biol 203:3603-3612

Bishop T, St-Pierre J, Brand MD (2002) Primary causes of decreased mitochondrial oxygen consumption during metabolic depression in snail cells. Am J Physiol 282:R372-R382

Boutilier RG, St-Pierre J (2002) Adaptive plasticity of skeletal muscle energetics in hibernating frogs: mitochondrial proton leak during metabolic depression. J Exp Biol 205:2287-2296

Brand MD (2005) The efficiency and plasticity of mitochondrial energy transduction. Biochem Soc Trans 33(pt 5):897-904

Brand MD, Chien LF, Diolez P (1994) Experimental discrimination between proton leak and redox slip during mitochondrial electron transport. Biochem J 297:27-29

Brand MD, Pakay JL, Ocloo J, Kokoszka DC, Brooks PS, Cornwall EJ (2005) The basal proton conductance of mitochondria depends on adenine nucleotide translocase content. Biochem J 392:353-362

Brooks PS (2005) Mitochondrial $\mathrm{H}^{+}$leak and ROS generation: an odd couple. Free Radic Biol 38:12-23

Brown JCL, Gerson AR, Staples JF (2007) Mitochondrial metabolism during daily torpor in the dwarf Siberian hamster: role of active regulated changes and passive thermal effects. Am J Physiol 293(5):R1833-R1845

Cadenzas S, Buckingham J, St-Pierre J, Dickenson K, Jones R, Brand M (2000) AMP decreases the efficiency of skeletal-muscle mitochondria. Biochem J 351:307-311

Cannon B, Nedergaard J (2004) Brown adipose tissue: function and physiological significance. Physiol Rev 64:277-359

Chance B, Williams GR (1955) A simple and rapid assay of oxidative phosphorylation. Nature 175:1120-1121

Duerr JM, Hillman SS (1993) An analysis of $\mathrm{pH}$ tolerance and substrate preference of isolated skeletal muscle mitochondria from Bufo marinus and Rana catesbeiana. Comp Biochem Physiol 106(4):889-893

Duong CA, Sepulveda CA, Graham JB, Dickson KA (2006) Mitochondrial proton leak rates in the slow, oxidative myotomal muscle and liver of the endothermic shortfin mako shark (Isurus oxyrinchus) and the ectothermic blue shark (Prionace glauca) and leopard shark (Triakis semifasciata). J Exp Biol 209:2678-2685

Fangue NA, Richards JG, Schulte PM (2009) Do mitochondrial properties explain intraspecific variation in thermal tolerance? J Exp Biol 212:514-522

Groen AK, Wanders RJ, Westerhoff HV, van der Meer R, Tager JM (1982) Quantification of the contribution of various steps to the control of mitochondrial respiration. J Biol Chem 257(66):2754-2757

Hafner RP, Brown GC, Brand MD (1990) Analysis of the control of respiration rate, phosphorylation rate, proton leak rate and proton motive force in isolated mitochondria using the 'top-down' approach of metabolic control theory. Eur J Biochem 188(2):313319
Heise K, Puntarulo S, Portner H, Abele D (2003) Production of reactive oxygen species by isolated mitochondria of the Antarctic bivalve Laternula elliptica (King and Broderip) under heat stress. Comp Biochem Biophys C 134(1):79-90

Hochachka PW, Somero GN (2002) Biochemical adaptation, mechanism and process in physiological evolution. Oxford University Press, New York

Hodges TK, Leonard RT (1974) Purification of a plasma membranebound adenosine triphosphatase from plant roots. Methods Enzymol 32(part B):392-406

Janssen AJM, Trijbels FM, Sengers RCA, Smeitink JAM, Van Den Heuvel LP, Wintjes TM, Stoltenborg-Hogenkamp BJM, Rodenburg JT (2007) Spectrophotometric assay for complex I of the respiratory chain in tissue samples and cultured fibroblasts. Clin Chem 53:729-734

Jastroch M, Buckingham J, Helwig M, Klingenspor M, Brand M (2007) Functional characterization of UCP1 in the common carp: uncoupling activity in liver mitochondria and cold-induced expression in the brain. J Comp Physiol B 177(7):743-752

Kadenbach B (2003) Intrinsic and extrinsic uncoupling of oxidative phosphorylation. Biochim Biophys Acta 1604:77-94

Kadenbach B, Ramzan R, Wen L, Vogt S (2009) New extension of the Mitchell theory for oxidative phosphorylation in mitochondria of living organisms. Biochim Biophys Acta. doi:10.1016/ j.bbagen.2009.04.019

Kayes SM, Cramp RL, Hudson NJ, Franklin CE (2009) Surviving the drought: burrowing energy by increasing mitochondrial coupling. J Exp Biol 232:2248-2253

Korshunov SS, Skulachev VP, Starkov AA (1997) High protonic potential actuates a mechanism of production of reactive oxygen species in mitochondria. FEBS Lett 416(1):15-18

Kuznetsov AV, Schneeberger S, Seiler R, Brandacher G, Mark W, Steurer W, Saks V, Usson Y, Margreiter R, Gnaiger E (2004) Mitochondrial defects and heterogeneous cytochrome $c$ release after cardiac cold ischemia and reperfusion. Am J Physiol Heart Circ Physiol 286:H1633-H1641

Lea MS, Hillman SS (1990) Effects of osmolality and solutes on performance of shark heart mitochondria. J Exp Zool 255:9-15

McMullen DC, Storey KB (2008) Mitochondria of cold hardy insects: Responses to cold and hypoxia assessed at enzymatic, mRNA and DNA levels. Insect Biochem Mol Biol 38:367-373

Mishra R, Shukla S (1994) Effects of endosulfan on bioenergetic properties of liver-mitochondria from the fresh-water catfish Clarias batrachus. Pestic Biochem Physiol 50(3):240-246

Murphy MP, Brand MD (1987) The control of electron flux through cytochrome oxidase. Biochem J 243(2):499-505

Pagliarini DJ, Dixon JE (2006) Mitochondrial modulation: reversible phosphorylation takes center stage? $\mathrm{T}$ Biochem Sci 31(1):26-34

Papa S, Guerrieri F, Capitanio N (1997) A possible role of slips in cytochrome $c$ oxidase in the antioxygen defense system of the cell. Biosci Rep 17(1):23-31

Papa S, De Rasmo D, Scacco S, Signorile A, Technikova-Dobrova Z, Palmisano G, Sardanelli AM, Papa F, Panelli D, Scaringi R, Santeramo A (2008) Mammalian complex I: a regulable and vulnerable pacemaker in mitochondrial respiratory function. Biochim Biophys Acta 1777:719-728

Podrabsky JE (1999) Husbandry of the annual killifish Austrofundulus limnaeus with special emphasis on the collection and rearing of embryos. Environ Biol Fish 54:421-431

Podrabsky JE, Hand SC (1999) The bioenergetics of embryonic diapause in an annual killifish Austrofundulus limnaeus. J Exp Biol 202:2567-2580

Podrabsky JE, Hrbek T, Hand SC (1998) Physical and chemical characteristics of ephemeral pond habitats in the Maracaibo basin and Llanos region of Venezuela. Hydrobiologica 362:67-78 
Podrabsky JE, Lopez JP, Fan TWM, Higashi R, Somero GN (2007) Extreme anoxia tolerance in embryos of the annual killifish Austrofundulus limnaeus: insights from a metabolomics analysis. J Exp Biol 210:2253-2266

Reynolds JA, Hand SC (2004) Differences in isolated mitochondria are insufficient to account for respiratory depression during diapause in Artemia franciscana embryos. Physiol Biochem Zool 77(3):366-377

Rolfe D, Brand MD (1996) Contribution of mitochondrial proton leak to skeletal muscle respiration and to standard metabolic rate. Am J Physiol 271:C1380-C1389

Rosing J, Harris DA, Kemp A, Slater EC (1975) Nucleotide-binding properties of native and cold-treated mitochondrial ATPase. Biochim Biophys Acta 376:13-26

Savina MV, Gamper NL (1998) Respiration and adenine nucleotides of Baltic lamprey (Lampetra fluviatilis L.) hepatocytes during spawning migration. Comp Biochem Physiol B 120:375-383

Savina MV, Emelyanova LV, Belyaeva EA (2006) Bioenergetic parameters of lamprey and frog liver mitochondria during metabolic depression and activity. Comp Biochem Physiol B 145:296-305

Scott ID, Nicholls DG (1980) Energy transduction in intact synaptosomes. Biochem J 186:21-33

Storey KB, Hochachka PW (1974) Enzymes of energy metabolism from a vertebrate facultative anaerobe, Pseudemys scripta. Turtle heart phosphofructokinase. J Biol Chem 249(5):1417-1422
St-Pierre J, Brand MD, Boutilier RG (2000a) The effect of metabolic depression on proton leak rate in mitochondria from hibernating frogs. J Exp Biol 209:1469-1476

St-Pierre J, Brand MD, Boutilier RG (2000b) Mitochondria as ATP consumers: cellular treason in anoxia. Proc Natl Acad Sci 97:8670-8674

Stuart JA, Gillis TE, Ballantyne JS (1998) Compositional correlates of metabolic depression in the mitochondrial membranes of estivating snails. Am J Physiol 275:R1977-R1982

Trzcionka M, Withers KW, Klingenspor M, Jastroch M (2008) The effects of fasting and cold exposure on metabolic rate and mitochondrial proton leak in liver and skeletal muscle of an amphibian, the cane toad Bufo marinus. J Exp Biol 211:1911-1918

Villani G, Attardi G (1997) In vivo control of respiration by cytochrome $c$ oxidase in wild-type and mitochondrial DNA mutationcarrying human cells. Proc Natl Acad Sci 94(4):1166-1171

Wourms JP (1972a) Developmental biology of annual fishes. I. Stages in the normal development of Austrofundulus myersi Dahl. J Exp Zool 182:143-168

Wourms JP (1972b) The developmental biology of annual fishes III. Pre-embryonic and embryonic diapause of variable duration in the eggs of annual fishes. J Exp Zool 182:389-414 